\title{
Correspondence
}

\section{Understanding different cultures}

Sir: Drs Sheikh and Farooq raise several important issues that multidisciplinary teams need to consider when dealing with patients from ethnic minority groups (Psychiatric Bulletin, 1994, 18, 739). They err, however, in the tone of their article, which conveys a sense of absolutism and certainty, portraying minority communities in a way that confirms the stereotypes of the British media. For instance, while some mixed-race marriages do not work (and a third of white marriages do not, elther), the authors' assertion that "marriages across religious and racial boundaries cause immense difficulties for an individual" is too sweeping a generalisation to be of any relevance. Similarly, while some young people forced into arranged marriages against their will may become unhappy, the authors' statement that "it leads only to unhappiness, difficulties in adjustments, a life of existence rather than enjoyment" (my italics) completely ignores the fact that the majority of people from ethnic minorities have managed a successful transition across the cultural divide and do not spend their lives trapped in unmitigated misery.

This criticism may appear pedantic, and the authors' choice of words may only be to emphasise certain aspects of their basic argument. I think, though, that a wider reason may be the viewing of cultural difference as a static, impenetrable barrier between people that, if breached, can only lead to suffering and difficulties. Immigrant populations all over the world live in 'imaginary homelands'. While the country of origin may itself have undergone major cultural and economic changes, immigrant populations can continue to live by values that existed at the time of their departure from their country of origin. This is as true of Asian people in Britain as it is of British people settled in Calcutta or Singapore. Host populations then tend to view immigrants as rigid and accuse them of not integrating into the dominant culture, further strengthening the immigrant's desire to maintain a distinct cultural identity.
One way to resolve such differences is to accept the underlying unity of humanity across the diversity of cultures. For instance, some of the problems mentioned by the authors, such as issues around authority, the 'new generation', break-up of family bonds, etc., are problems that middle-aged and elderly white populations find equally distressing in their culture. All over the Western world, the dominant paradigm of rampant individualism is increasingly being challenged by communitarian politicians and sociologists who now extol the virtues of family and community. Differences between cultures need not necessarily be seen to be divisive or threatening to one or the other culture. Cultural diversity can, and should produce a sense of 'multiplicity of identity'. From personal experience, I can say that I find myself in many ways enhanced as an individual after moving to Britain, enriched both in my sense of identity, and my understanding of different cultures. I carry some 'Britishness' with me every time I visit India, while I continue to maintain a sense of being Indian while I live in Britain. Such a view of culture, which joins rather than divides, is the only way to reduce ignorance and prejudice, while ensuring that respect for different cultures will allow health professionals to cater appropriately to the cultural needs of all under their care.

SWARAN P. SinGH, Mapperley Hospital, Nottingham NG3 6AA

Sir: We feel that the objections made by $\mathrm{Dr}$ Singh to our statements make them seem rather sweeping, but if read in the whole context they only reflect the reality on the ground. We would like to share some of the philosophical idealism of Dr Singh's letter, and would very much want society to be as understanding as he proposes. In reality, when it comes down to psychiatric services and treatment of mental illness, one has to recognise the problems encountered by professionals when offering to provide a therapeutic service. 